\title{
sciendo
}

Int. J. of Applied Mechanics and Engineering, 2021, vol.26, No.3, pp.104-118

DOI: 10.2478/ijame-2021-0038

\section{EFFECTS OF PRESSURE GRADIENT ON CONVECTIVE HEAT TRANSFER IN A BOUNDARY LAYER FLOW OF A MAXWELL FLUID PAST A STRETCHING SHEET}

\author{
A.N. KASHIF \\ Department of Mathematical Sciences, Faculty of Science, Federal Urdu University of Arts \\ Science \& Technology, Karachi, PAKISTAN \\ F. SALAH \\ Department of Mathematics, College of Science and Arts, King Abdul-Aziz University
}

21911Rabigh, SAUDI ARABIA

\author{
D.S. SANKAR \\ School of Applied Sciences and Mathematics, Universiti Teknologi Brunei, Jalan Tungku Link Gadong \\ BE1410, BRUNEI DARUSSALAM
}

M.D.N. IZYAN

Faculty of Entrepreneurship and Business, Universiti Malaysia Kelantan, Pengkalan Chepa, 16100 Kota Bharu, Kelantan, MALAYSIA

\section{K.K. VISWANATHAN*}

Ship \& Offshore Extreme Technology Industry-Academy Cooperation Research Centre

Department of Naval Architecture \& Ocean Engineering, Inha University

100 Inha ro, Micheulol-gu, Incheon, REPUBLIC OF KOREA

E-mail:visu20@yahoo.com; viswanathan@utm.my

\begin{abstract}
The pressure gradient term plays a vital role in convective heat transfer in the boundary layer flow of a Maxwell fluid over a stretching sheet. The importance of the effects of the term can be monitored by developing Maxwell's equation of momentum and energy with the pressure gradient term. To achieve this goal, an approximation technique, i.e. Homotopy Perturbation Method (HPM) is employed with an application of algorithms of Adams Method (AM) and Gear Method (GM). With this approximation method we can study the effects of the pressure gradient $(m)$, Deborah number $(\beta)$, the ratio of the free stream velocity parameter to the stretching sheet parameter $(\varepsilon)$ and Prandtl number $(\operatorname{Pr})$ on both the momentum and thermal boundary layer thicknesses. The results have been compared in the absence and presence of the pressure gradient term $m$. It has an impact of thinning of the momentum and boundary layer thickness for non-zero values of the pressure gradient. The convergence of the system has been taken into account for the stretching sheet parameter $\varepsilon$. The result of the system indicates the significant thinning of the momentum and thermal boundary layer thickness in velocity and temperature profiles. On the other hand, some results show negative values of $f^{\prime}(\eta)$ and $\theta(\eta)$, which indicates the case of fluid cooling.
\end{abstract}

Key words: Homotopy Perturbation Method (HPM), pressure gradient parameter, convective heat transfer, Maxwell fluid, stretching sheet.

\footnotetext{
${ }^{*}$ To whom correspondence should be addressed
} 


\section{Introduction}

The connective heat transfer phenomena are the subject of research which has attracted several researchers due to numerous industrial and biological engineering applications such as compulsive convection in conduits, production of papers, fibre glass, different types of paints, and electronic chips, material processing, crystal growth, nuclear reactor cooling, food processing and movement of biological fluids, drilling muds, shampoo, ketchup, cement, sludge, grease, granular suspension, aqueous foams, slurries, plastics, etc. [1, 2]. Although a lot of investigation has been done on the convective heat transfer in the boundary layer flow, there will always be room for deeper and wider understanding of these phenomena. Fathizadeh and Rashidi [3], Aziz [4], Ishak [5] and Shagaiya and Daniel [6] studied the convective heat transfer in the boundary layer flow of Newtonian fluids. In recent years, Bhattacharyya et al. [2], Surati and Timol [7], Patel and Timol [8] and Hayat et al. [9] used non-Newtonian fluids to analyse the convective heat transfer in the boundary layer flows.

Hayat et al. [1], Malik et al. [10], Singh and Agarwal [11], Javed et al. [12], Shateyi [13], Mukhopadhyay [14], Bhattacharyya [15], Ibrahim and Suneetha [16], Rehman and Nadeem [17] and Saleh et al. [18] theoretically studied the behaviour of the fluid flow and boundary layer thickness along with the convective heat transfer in the flow of Newtonian and non-Newtonian fluids over a stretching sheet with various boundary conditions and parameters, but they did not discuss the effects of the pressure gradient on various rheological quantities.

The Homotopy Perturbation Method (HPM) is an effective and powerful analytical method which was first developed by Ji-Huan [19] for solving nonlinear differential equations. It has been well established that the analytical solutions obtained through this method converge rapidly [20]. As an approximation technique, several researchers [20-23] have applied it to solve various kinds of nonlinear differential equations and also to solve problems from several branches of engineering and biological sciences. Later on, this method was significantly improved by Ji-Huan [20] and other researchers [24-26].

Fan et al. [27] and Ishak in [28] propounded that their analytical solution to temperature profile converges to 0 for a wide range of values of the free convective parameter $\gamma$ and the unsteadiness parameter, respectively $A$. Bhattacharyya et al. in $[29,30]$ analysed the effects of slip velocity at the boundary on the heat transfer in the stagnation point flow over a stretching sheet. Motsa and Sibanda in [31] obtained semi-analytical solution to the MHD flow over a nonlinear stretching sheet. Rahman et al. [32] investigated heat transfer characteristics in a micropolar fluid flow along a non-linear stretching sheet with a temperature-dependent viscosity and variable surface temperature. Hayat et al. in [33] analysed the mixed convection stagnation point flow of a Casson fluid with convective boundary conditions. Kazem et al. in [34] derived the analytical solutions to a stagnation-point flow past a porous stretching sheet with heat generation and used several parameters such as the porosity parameter $M$, the stretching parameter $C$, the Prandtl number $\operatorname{Pr}$ and the dimensionless heat generation/absorption coefficient $B$ to study the convergence of the obtained analytical solution. To the knowledge of the authors the effects of the pressure gradient on the convective heat transfer in a boundary layer flow of a Maxwell fluid past a stretching sheet have not been studied yet, and thus it is proposed to study the effects of the pressure gradient on the convective hear transfer of a non-Newtonian Maxwell fluid.

The present study employs He's HPM to obtain the approximate analytical solution to the convective heat transfer in the boundary layer flow of a Maxwell fluid over a stretching sheet in the presence and absence of the pressure gradient. To obtain the solution of this problem, two main algorithms such as Adams Method (AM) [35] and Gear Method (GM) [36] have been used [37] with an application of HPM. The effect of the pressure gradient $m$ on the velocity and temperature profiles is analysed for different values of the Deborah number $\beta$, the ratio of the stretching velocity parameter $\varepsilon$ and Prandtl numbers $\operatorname{Pr}$. To the knowledge of the authors, the proposed research problem has not been studied so far.

\section{Basics of HPM}

The solution methodology of the HPM is explained hereunder: Consider the nonlinear differential equation 


$$
A(u)-f(r)=0, \quad r \in \Omega,
$$

along with the boundary conditions

$$
B(u, \partial u / \partial n)=0, \quad r \in \Gamma
$$

where $A(u)$ is a differential operator, $B$ is the boundary condition, $f(r)$ is an analytic function, $\Omega$ is the boundary of the domain $\Gamma$. The differential operator $A(u)$ in Eq.(2.1) can be split into two parts, such as the linear differential operator $L(u)$ and nonlinear differential operator $N(u)$, therefore, Eq.(2.1) reduces to the form given below:

$$
L(u)+N(u)-f(r)=0
$$

By the HPM [10, 37], a homotopy $v(r, P): \Omega \times[0,1] \rightarrow R$ is constructed, which satisfies

$$
H(v, p)=(1-p)\left[L(v)-L\left(u_{o}\right)\right]+p[A(v)-f(r)]=0, \quad p \in[0,1], \quad r \in \Omega
$$

or

$$
H(v, p)=L(v)-L\left(u_{o}\right)+p L\left(u_{o}\right)+p[N(v)-f(r)]=0
$$

where $p \in[0,1]$ is a parameter which is embedded, $u_{o}$ is the initial approximated solution of Eq.(2.1), where the boundary conditions are fulfilled. Clearly, from Eq.(2.4) or Eq.(2.5), $H$ takes the following forms:

$$
\begin{aligned}
& H(v, 0)=L(v)-L\left(u_{o}\right)=0, \\
& H(v, 1)=A(v)-f(r)=0 .
\end{aligned}
$$

The transformation of $p$ from 0 to $l$ is referred to as $v(r, p)$ from $u_{o}(r)$ to $u(r)$. Topologically, this is known as a deformation, besides $L(v)-L\left(u_{o}\right), A(v)-f(r)$ are termed as homotopic. In this study, the embedding parameter $p$ is a small parameter. Assume that the solution of Eq.(2.4) or Eq.(2.5) can be written as a power series in $p$ :

$$
v=v_{0}+p v_{1}+p^{2} v_{2}+\ldots
$$

Setting $p=1$ results in the approximate solution of Eq.(2.1), we get

$$
u=\lim _{p \rightarrow 1} v=v_{0}+v_{1}+v_{2}+\ldots
$$

The coupling of the perturbation method and the homotopy method is called the homotopy perturbation method, which has eliminated limitations of the traditional perturbation methods. On the other hand, the proposed technique can take full advantage of the traditional perturbation techniques. 


\section{Mathematical formulation}

Consider the convective heat transfer in the boundary layer flow of a Maxwell fluid over a stretching sheet in the presence of the pressure gradient which is governed by the continuity and the momentum equations. The governing equations of continuity, momentum and energy may be written in usual notation as $[2,38]$ :

$$
\begin{aligned}
& \frac{\partial u}{\partial x}+\frac{\partial v}{\partial y}=0 \\
& u \frac{\partial u}{\partial x}+v \frac{\partial v}{\partial y}+\lambda\left[u^{2} \frac{\partial^{2} u}{\partial x^{2}}+v^{2} \frac{\partial^{2} v}{\partial y^{2}}+2 u v \frac{\partial^{2} u}{\partial x \partial y}\right]=-\frac{1}{\rho} \frac{d P}{d x}+v \frac{\partial^{2} u}{\partial x^{2}} \\
& u \frac{\partial T}{\partial x}+v \frac{\partial T}{\partial y}=\frac{\kappa}{\rho c_{P}} \frac{\partial^{2} T}{\partial y^{2}}
\end{aligned}
$$

where $u$ and $v$ are the components of velocity in the $x$ and $y$ directions, respectively, $v$ is the kinematic fluid viscosity, $\rho$ is the fluid density, $\mu$ is the coefficient of fluid viscosity, $\lambda$ is the relaxation time, $T$ is the temperature, $\kappa$ is the fluid thermal conductivity and $c_{p}$ is the specific heat. Subject to the boundary conditions:

$$
\begin{aligned}
& u=U_{w}(x)=a x^{m}, \quad v=0, \quad T=T_{w} \quad \text { at } \quad y=0, \quad \eta=0, \\
& u=U_{\infty}(x)=b x^{m}, \quad v=0, \quad T \rightarrow T_{\infty} \quad \text { at } \quad y \rightarrow \infty, \quad \eta=\eta_{\infty} .
\end{aligned}
$$

Now, the stream function $\psi(x, y)$ is introduced as:

$$
u=\frac{\partial \psi}{\partial y}, \quad v=-\frac{\partial \psi}{\partial x}
$$

For an external flow $-\frac{1}{\rho} \frac{d P}{d x}$ can be replaced by $U_{\infty} \frac{d U_{\infty}}{d x}$, and taking into consideration Eq.(3.5), Eq.(3.1) is identically satisfied and Eqs (3.2) and (3.3) can be reduced to the following forms:

$$
\begin{aligned}
& \frac{\partial \psi}{\partial y} \frac{\partial^{2} \psi}{\partial x \partial y}-\frac{\partial \psi}{\partial x} \frac{\partial^{2} \psi}{\partial y^{2}}+\lambda\left[\left(\frac{\partial \psi}{\partial y}\right)^{2} \frac{\partial^{2} \psi}{\partial x \partial y}+\left(\frac{\partial \psi}{\partial x}\right)^{2} \frac{\partial^{3} \psi}{\partial y^{3}}+\right. \\
& \left.-2 \frac{\partial \psi}{\partial y} \frac{\partial \psi}{\partial x} \frac{\partial^{3} \psi}{\partial x \partial y^{2}}\right]=U_{\infty} \frac{d U_{\infty}}{d x}+v \frac{\partial^{3} \psi}{\partial y^{3}}
\end{aligned}
$$

and

$$
\frac{\partial \psi}{\partial y} \frac{\partial T}{\partial x}-\frac{\partial \psi}{\partial x} \frac{\partial T}{\partial y}=\frac{\kappa}{\rho c_{P}} \frac{\partial^{2} T}{\partial y^{2}}
$$


Here, we have introduced the dimensionless variables as below:

$$
\begin{aligned}
& \eta=y \sqrt{\frac{U_{w}(x)}{v x}}, \quad \psi=f(\eta) \sqrt{v x U_{w}(x)}, \\
& \theta(\eta)=\frac{T-T_{\infty}}{T_{w}-T_{\infty}} \quad \text { and } \quad\left\{U_{\infty}(x)=b x^{m}, m=\frac{x}{U_{\infty}(x)} \frac{d U_{\infty}(x)}{d x}\right\} .
\end{aligned}
$$

Based on Eq.(3.8), we have used similarity transformation to reduce the governing differential equations; Eq.(3.6) and Eq.(3.7) to ordinary non-linear differential equations, Eq.(3.9) and Eq.(3.10), respectively.

$$
\begin{aligned}
& f^{\prime \prime}+m\left(1-f^{\prime 2}\right)+\left(\frac{m+1}{2}\right) f f^{\prime \prime}-\frac{\beta}{2}[(m-1)(3-m)) \eta f^{\prime 2} f^{\prime \prime}+4 m(m+1) f^{\prime 3}+ \\
& \left.+(m+1)^{2} f^{2} f^{\prime \prime \prime}-2(m+1)(3 m-1) f^{\prime} f^{\prime \prime}\right]=0, \\
& \theta^{\prime \prime}+\frac{\operatorname{Pr}(m+1)}{2} f \theta^{\prime}=0
\end{aligned}
$$

where $\beta=\lambda U_{\infty}(x) / 2 x$ is the Deborah number [39] and $\operatorname{Pr}=\mu c_{p} / \kappa$ is the Prandtl number [40]. The boundary conditions are obtained from the similarity variables as given below:

$$
f(0)=0, \quad \eta=f^{\prime}(0)=1, \quad f^{\prime}\left(\eta_{\infty}\right)=\varepsilon, \quad \theta(0)=1, \quad \theta\left(\eta_{\infty}\right)=0
$$

where $\varepsilon=\frac{b}{a}, b$ is the free stream velocity parameter, $a$ is the stretching sheet parameter, $\varepsilon$ is the ratio of the free stream velocity parameter to the stretching sheet parameter.

\section{HPM Solution}

According to the HPM method from Eqs (3.9) and (3.10) we get:

$$
\begin{aligned}
& (1-p)\left(f^{\prime \prime \prime}-f^{\prime \prime \prime}\right)+p f^{\prime \prime \prime}+\left(\frac{m+1}{2}\right) f f^{\prime \prime}+m\left(1-f^{\prime 2}\right)-\frac{\beta}{2}\left[(m-1)(3-m) \eta f^{\prime 2} f^{\prime \prime}\right. \\
& \left.+4 m(m+1) f^{\prime 3}+(m+1)^{2} f^{2} f^{\prime \prime \prime}-2(m+1)(3 m-1) f f^{\prime} f^{\prime \prime}\right]=0 . \\
& (1-p)\left(\theta^{\prime \prime}-\theta^{\prime \prime}{ }_{0}\right)+p\left(\theta^{\prime \prime}+\frac{\operatorname{Pr}(m+1)}{2} f^{\prime}\right)=0 \\
& f=f_{0}+p f_{1}+p^{2} f_{2}+\ldots . . \\
& \theta=\theta_{0}+p \theta_{1}+p^{2} \theta_{2}+\ldots . .
\end{aligned}
$$


Assuming $f^{\prime \prime \prime}=0, \theta^{\prime \prime}=0$, and using Eq.(3.11), Eq.(4.3) and Eq.(4.4) in Eqs (4.1)-(4.2) and then simplifying the resulting equations and thereafter equating the terms involving the like powers of $p$-terms, we have the following equations:

$$
\begin{aligned}
& p^{0}: f^{\prime \prime \prime}=0, \quad f_{0}(0)=0, \quad f_{0}{ }^{\prime}(0)=1, \quad f_{0}{ }^{\prime}\left(\eta_{\infty}\right)=\varepsilon, \\
& \theta_{0}^{\prime \prime}=0, \quad \theta_{0}(0)=1, \quad \theta_{0}\left(\eta_{\infty}\right)=0 \\
& p^{1}: f_{1}^{\prime \prime \prime}=m\left(f_{0}^{\prime 2}-1\right)-\left(\frac{m+1}{2}\right) f_{0} f_{0}^{\prime \prime}+2 m(m+1) \beta f_{0}^{\prime 2}+\left(1-2 m-3 m^{2}\right) \beta f_{0} f_{0}^{\prime} f_{0}^{\prime \prime}+ \\
& +\frac{1}{2}\left(4 m-3 \eta-m^{2} \eta\right) \beta f_{0}^{\prime 2} f_{0}^{\prime \prime}, \quad f_{l}(0)=0, \quad f_{l}^{\prime}(0)=1, \quad f_{l}^{\prime}\left(\eta_{\infty}\right)=\varepsilon, \\
& \theta_{1}^{\prime \prime}=-\frac{\operatorname{Pr}(m+1)}{2} f_{0} \theta_{0}^{\prime}, \quad \theta_{l}(0)=0, \quad \theta_{l}\left(\eta_{\infty}\right)=0, \\
& p^{2}: f_{2}^{\prime \prime \prime}=2 m f_{0}^{\prime} f_{1}^{\prime}-\left(\frac{m+1}{2}\right)\left(f_{1} f_{0}^{\prime \prime}+f_{0} f_{1}^{\prime \prime}\right) 6 \beta m(m+1) f_{0}^{\prime 2} f_{1}^{\prime}+ \\
& +\left(1-2 m-3 m^{2}\right) \beta \times\left(f_{0}^{\prime} f_{1} f_{0}^{\prime \prime}+f_{0} f_{0}^{\prime} f_{1}^{\prime \prime}+f_{0} f_{1}^{\prime} f_{0}^{\prime \prime}\right)+\eta \beta\left(-3+4 m-m^{2}\right)+ \\
& +\left(f_{0} f_{1}^{\prime} f_{0}^{\prime \prime}+\frac{1}{2} f_{0}^{\prime 2} f_{1}^{\prime \prime}\right)+\beta \frac{(m+1)^{2}}{2} f_{0}^{\prime 2} f_{1}^{\prime \prime \prime}, \\
& f_{2}(0)=0, \quad f_{2}{ }^{\prime}(0)=1, \quad f_{2}{ }^{\prime}\left(\eta_{\infty}\right)=\varepsilon, \quad \theta_{2}^{\prime \prime}=-\frac{\operatorname{Pr}(m+1)}{2}\left(f_{0} \theta_{1}^{\prime}+f_{1} \theta_{0}^{\prime}\right), \\
& \theta_{2}(0)=0, \quad \theta_{2}\left(\eta_{\infty}\right)=0, \\
& p^{3}: f_{3}^{\prime \prime \prime}=m f_{1}^{\prime 2}+2 m f_{0}^{\prime} f_{2}^{\prime}-\left(\frac{m+1}{2}\right)\left(f_{2} f_{0}^{\prime \prime}+f_{1} f_{1}^{\prime \prime}+f_{0} f_{2}^{\prime \prime}\right)+6 \beta m(m+1) \times \\
& \times\left(f_{1}^{\prime 2} f_{0}^{\prime}+f_{0}^{\prime 2} f_{2}^{\prime}\right)\left(1-2 m-3 m^{2}\right) \beta \times\left(f_{0}^{\prime} f_{2} f_{0}^{\prime \prime}+f_{1} f_{1}^{\prime} f_{0}^{\prime \prime}+f_{0} f_{2}^{\prime} f_{0}^{\prime \prime}+f_{0}^{\prime} f_{1} f_{1}^{\prime \prime}+\right. \\
& \left.+f_{1}^{\prime} f_{0} f_{1}^{\prime \prime}+f_{0}^{\prime} f_{0} f_{2}^{\prime \prime}\right)+\eta \beta\left(-3+4 m-m^{2}\right)\left(f_{0}^{\prime} f_{2}^{\prime} f_{0}^{\prime \prime}+\frac{1}{2} f_{1}^{\prime 2} f_{0}^{\prime \prime}+f_{0}^{\prime} f_{1}^{\prime \prime} f_{1}^{\prime \prime}+\frac{1}{2} f_{0}^{\prime 2} f_{2}^{\prime \prime}\right)+ \\
& +\beta\left(1+2 m+m^{2}\right)\left(f_{0} f_{1} f_{1}^{\prime \prime \prime}+\frac{1}{2} f_{0}^{2} f_{2}^{\prime \prime \prime}\right), \\
& f_{3}(0)=0, \quad f_{3}{ }^{\prime}(0)=1, \quad f_{3}{ }^{\prime}\left(\eta_{\infty}\right)=\varepsilon, \\
& \theta_{3}^{\prime \prime}=-\frac{\operatorname{Pr}(m+1)}{2}\left(f_{0} \theta_{2}^{\prime}+f_{1} \theta_{1}^{\prime}+f_{2} \theta_{0}^{\prime}\right), \quad \theta_{3}(0)=0, \quad \theta_{3}\left(\eta_{\infty}\right)=0 .
\end{aligned}
$$


Solving Eqs (4.5)-(4.9), we get

$$
\begin{aligned}
& f_{0}=\frac{1}{2 \eta_{\infty}}\left(-\eta^{2}+2 \eta \eta_{\infty}+\eta^{2} \varepsilon\right) \\
& f_{1}=\frac{1}{480 \eta_{\infty}^{2}}\left(4 \beta \eta^{6}-2 \beta \eta^{5} \eta_{\infty}+10 \beta \eta^{4} \eta_{\infty}^{2}-2 \beta \eta^{2} \eta_{\infty}^{4}-4 \beta \eta^{6} \varepsilon^{3}+\right. \\
& \left.-12 \beta \eta^{2} \varepsilon^{3} \eta_{\infty}^{4}+12 \beta \eta^{6} \varepsilon^{2}-12 \beta \eta^{5} \varepsilon^{2} \eta_{\infty}-6 \beta \eta^{2} \varepsilon^{2} \eta_{\infty}^{4}-\ldots\right) \\
& f_{2}=\frac{1}{2419200 \eta_{\infty}^{5}}\left(2772 m^{3} \beta^{2} \varepsilon^{5} \eta^{10}-1596 m^{2} \beta^{2} \varepsilon^{5} \eta^{10}+2828 \beta^{2} \varepsilon^{5} \eta^{10}-868 \beta^{2} \varepsilon^{5} \eta^{10}+\right. \\
& \left.-13860 m^{3} \beta^{2} \varepsilon^{4} \eta^{10}+7980 m^{2} \beta^{2} \varepsilon^{4} \eta^{10}-14140 m \beta^{2} \varepsilon^{4} \eta^{10}+4340 \beta^{2} \varepsilon^{4} \eta^{10}+\ldots\right), \\
& f_{3}=\eta+\frac{\eta^{2}}{83026944000 \eta_{\infty}}\left(-92085840 m^{5} \beta^{3} \varepsilon^{7} \eta_{\infty}^{6}+664356000 m^{4} \beta^{2} \varepsilon^{4} \eta^{10}+\right. \\
& \left.+2319791936 m^{3} \beta^{3} \varepsilon^{7} \eta_{\infty}^{6}+\ldots . . .\right)-\frac{1}{4838400 \eta_{\infty}^{7}}\left(-\frac{2848 \beta^{3} \eta^{14}}{13}+\frac{3353}{3} \beta^{2} \eta^{4} \varepsilon^{5} \eta_{\infty}^{10}+\right. \\
& +\frac{19936}{13} \beta^{3} \eta^{14} \varepsilon+\frac{9966}{13} \beta^{3} \eta^{14} m^{5}+5775 \beta^{3} \eta^{4} m^{5} \varepsilon^{5} \eta_{\infty}^{10}+3465 \beta^{2} \eta^{4} m^{4} \varepsilon^{5} \eta_{\infty}^{10}+ \\
& +\frac{38824}{39} \beta^{3} \eta^{14} m^{3}-\frac{186634}{3} \beta^{3} \eta^{4} m^{3} \varepsilon^{5} \eta_{\infty}^{10}+\frac{30542}{39} \beta^{3} \eta^{14} m-\frac{57379}{3} \beta^{3} \eta^{4} m \varepsilon^{5} \eta_{\infty}^{10}+ \\
& \left.-\frac{231794}{39} \beta^{3} \eta^{14} m \varepsilon+\ldots\right) \\
& \theta_{0}=\frac{1}{\eta_{\infty}}\left(\eta_{\infty}-\eta\right) \\
& \theta_{1}=\frac{1}{48 \eta_{\infty}^{2}}\left(-\eta^{4} m \operatorname{Pr}+4 \eta^{3} m \operatorname{Pr} \eta_{\infty}-3 \eta m \operatorname{Pr} \eta_{\infty}^{3}+\eta^{4} m \operatorname{Pr} \varepsilon+\right. \\
& \left.-\eta m \operatorname{Pr} \varepsilon \eta_{\infty}^{3}-\eta^{4} \operatorname{Pr}+4 \eta^{3} \operatorname{Pr} \eta_{\infty}-3 \eta \operatorname{Pr} \eta_{\infty}^{3}+\eta^{4} \operatorname{Pr} \varepsilon-\eta \operatorname{Pr} \varepsilon \eta_{\infty}^{3}\right), \\
& \theta_{2}=\frac{1}{80640 \eta_{\infty}^{4}}\left(18 m^{2} \operatorname{Pr} \beta \varepsilon^{3} \eta^{8}+12 m \operatorname{Pr} \beta \varepsilon^{3} \eta^{8}-6 \operatorname{Pr} \beta \varepsilon^{3} \eta^{8}-54 m^{2} \operatorname{Pr} \beta \varepsilon^{2} \eta^{8}+\right. \\
& \left.-36 m \operatorname{Pr} \beta \varepsilon^{2} \eta^{8}+18 \operatorname{Pr} \beta \varepsilon^{2} \eta^{8}-18 m^{2} \operatorname{Pr} \beta \eta^{8}-12 m \operatorname{Pr} \beta \eta^{8}+\ldots\right) \text {, } \\
& \theta_{3}=\frac{1}{638668800 \eta_{\infty}^{6}}\left(23184 m \eta \operatorname{Pr} \beta^{2} \varepsilon^{3} \eta_{\infty}^{11}+2772 m^{4} \operatorname{Pr} \beta^{2} \eta^{12}+\right. \\
& +149688 \operatorname{Pr} \beta^{2} \eta \varepsilon^{5} \eta_{\infty}^{11}-1176 m^{3} \operatorname{Pr} \beta^{2} \eta^{12}-770472 \operatorname{Pr} m^{3} \beta^{2} \eta \varepsilon^{5} \eta_{\infty}^{11}+ \\
& -1232 m^{2} \operatorname{Pr} \beta^{2} \eta^{12}-211464 m^{2} \eta \varepsilon^{5} \operatorname{Pr} \beta^{2} \eta_{\infty}^{11}+6160 \beta^{2} \eta^{12} m^{2} \operatorname{Pr} \varepsilon+ \\
& \left.-1960 \beta^{2} \eta^{12} m \operatorname{Pr}+569160 \operatorname{Pr} m \beta^{2} \eta \varepsilon^{5} \eta_{\infty}^{11}+9700 \beta^{2} \eta^{12} m \operatorname{Pr} \varepsilon+\ldots\right) \text {. }
\end{aligned}
$$




\section{Results and discussion}

The primary objective of this study is to discuss the effects of various flow parameters such as the pressure gradient $(m)$, dimensionless variable $\left(\eta_{\infty}\right)$, the ratio of the free stream velocity parameter to the stretching sheet parameter $(\varepsilon)$, Deborah number $(\beta)$ and Prandtl number $(\operatorname{Pr})$ on the important rheological measurements such as velocity and temperature profiles. The analytic solutions obtained in Eqs (4.10)-(4.16) are evaluated for different values of the parameters to obtain data for plotting appropriate graphs and then the results are analysed.

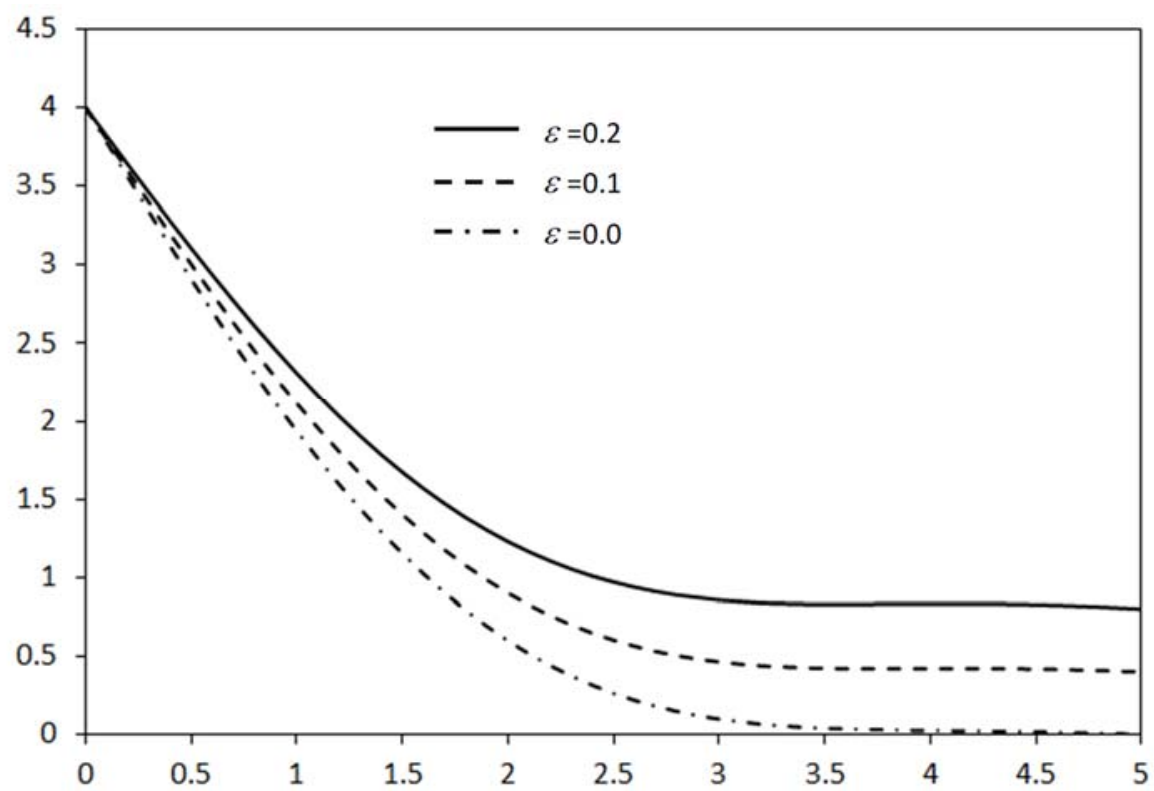

Fig.1. Velocity profile for $f^{\prime}(\eta)$ for different values of $\varepsilon$ when $\beta=-0.1, m=0$ and $\eta_{\infty}=5$.

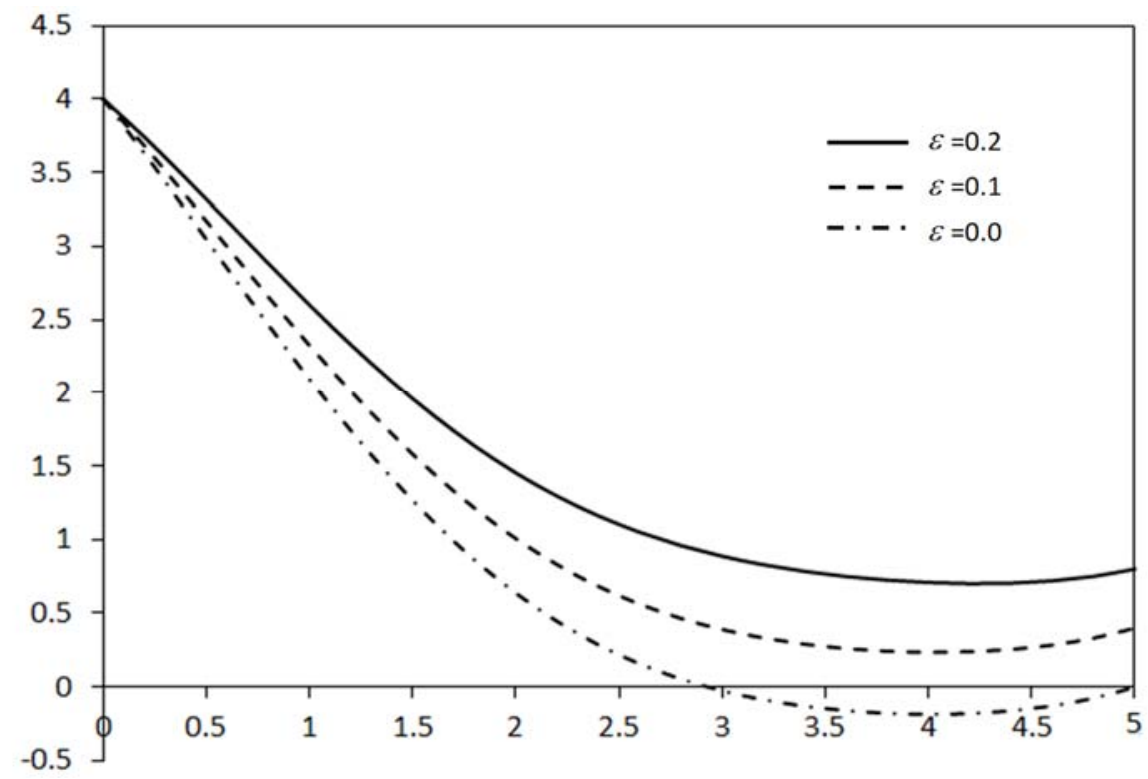

Fig.2. Velocity profile for $f^{\prime}(\eta)$ for different values of $\varepsilon$ when $\beta=-0.1, m=-0.2$ and $\eta_{\infty}=5$. 


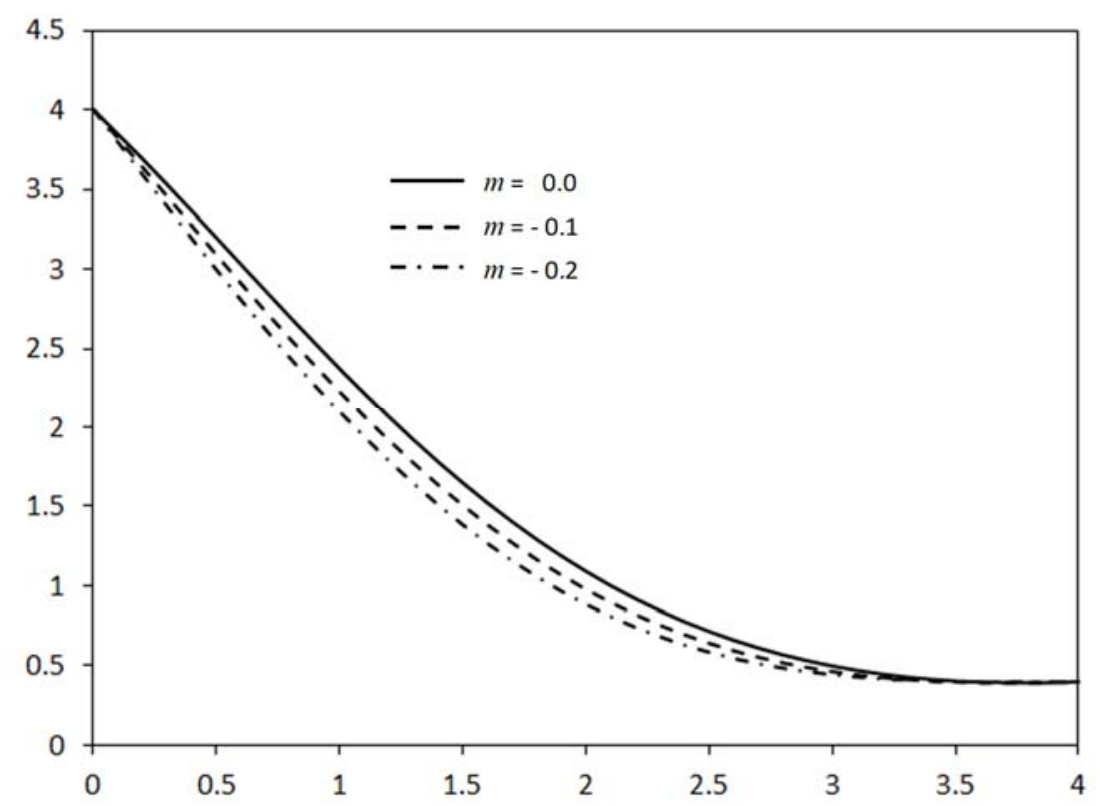

Fig.3. Velocity profile for $f^{\prime}(\eta)$ for different values of $m$ when $\beta=-0.1, \varepsilon=0.1$ and $\eta_{\infty}=4$.

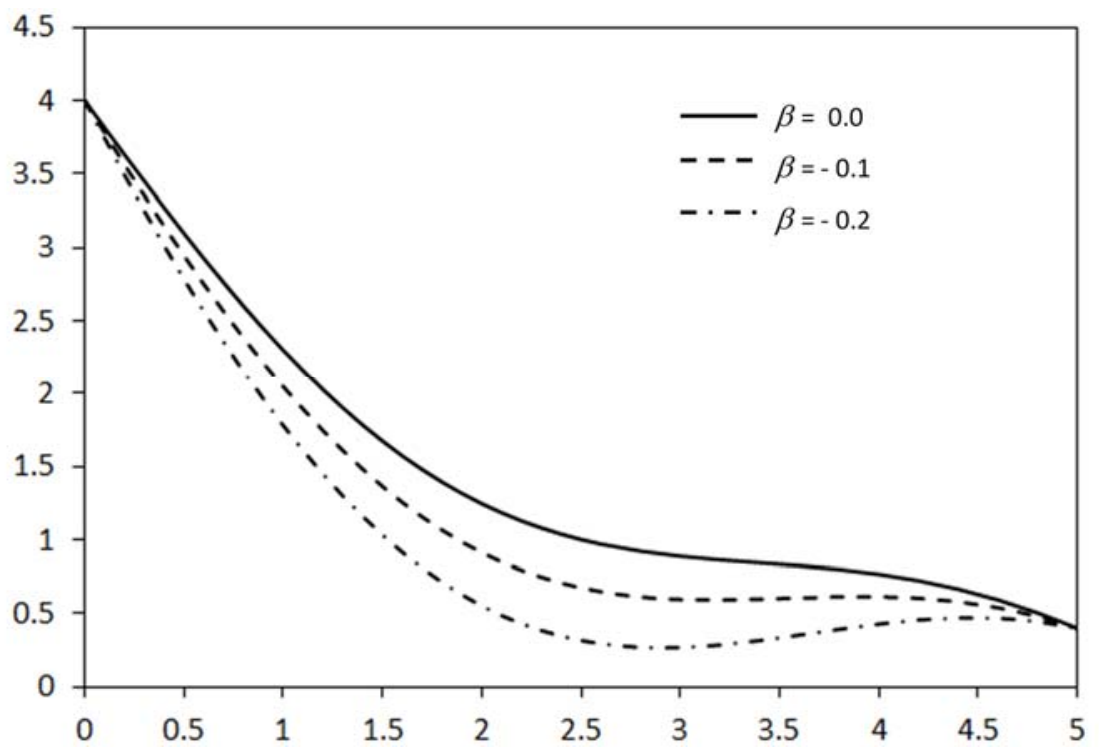

Fig.4. Velocity profile $f^{\prime}(\eta)$ for different values of $\beta$ when $m=0.1, \varepsilon=0.1$ and $\eta_{\infty}=5$.

The solution system has become convergent for the considered values of $\varepsilon$ as discussed in Fig.1. for the velocity profile. As $\varepsilon$ is a ratio, it converges to the ratio value 0.4 instead of converging to $0.1,0.2$ or 0.8 , since in the present study, boundary layer thickness ranges from 4 for the value of $f^{\prime}(\eta)$, whereas as reported earlier, it starts from 1 (as mentioned in Section 1). For the temperature profile, it is shown to be convergent to " 0 " for the considered values of $\varepsilon$ as shown in Fig.5. These results are similar to the cases discussed in Section 1. Reported results are in the presence and absence of the pressure gradient $m$ for the sake of comparison. In Figs 1 and 2, we have plotted velocity profiles for $m=0$ and $m=-0.2$ respectively. In Fig.1., it can be observed that the momentum boundary layer thickness decreases with the decreasing value of $\varepsilon$. The boundary layer thickness becomes significantly thinner. Note that in Fig.2., a curve for 
$\varepsilon=0$ shows some negative values for $f^{\prime}(\eta)$. This is the case of fluid cooling. It is possible when the buoyancy force opposes the stretching motion of the surface, thus the fluid flow caused by the upward motion of the surface is opposed by the free convection currents which were induced by the buoyancy force and hence $f^{\prime}(\eta)$ decreases [27].

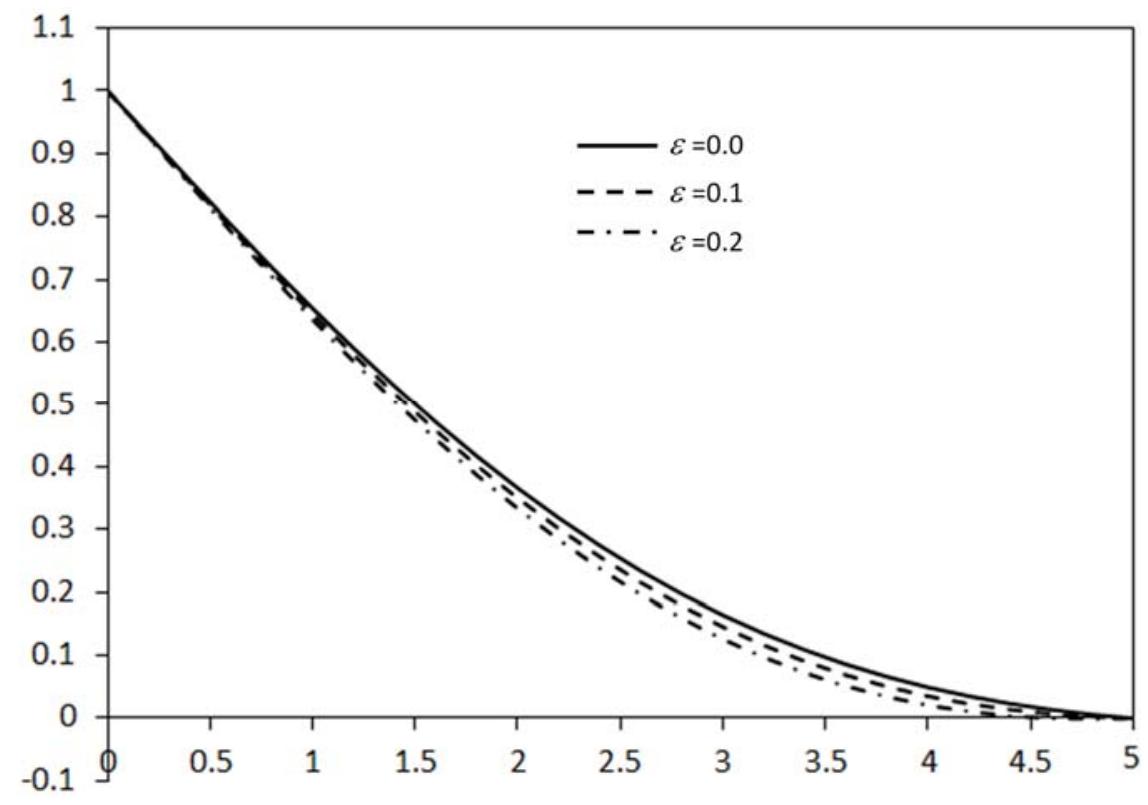

Fig.5. Energy profile for $\theta(\eta)$ for different values of at $\eta_{\infty}=5, \beta=-0.1, m=0$ and $\operatorname{Pr}=0.3$.

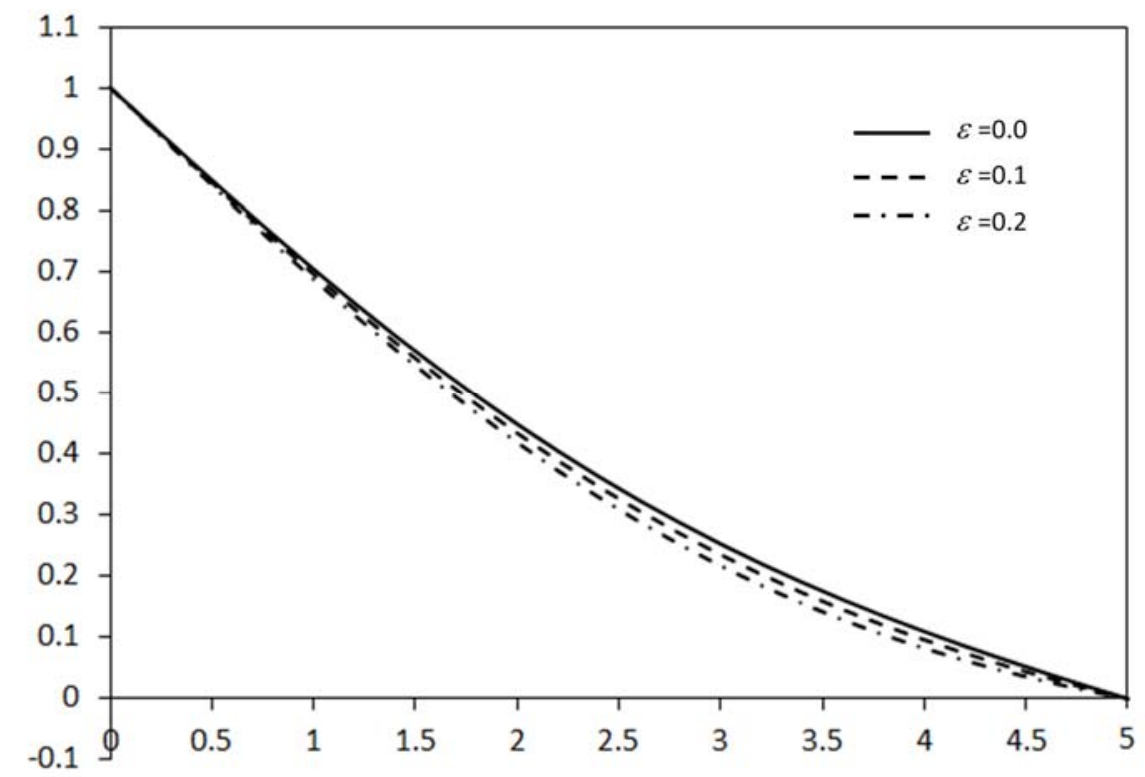

Fig.6. Energy profile for $\theta(\eta)$ for different values of at $\eta_{\infty}=5, \beta=-0.1, m=-0.2$ and $\operatorname{Pr}=0.3$.

Figure 3 shows the increasing behaviour of the fluid flow for the decreasing values of $m$ and thus the thickness of the boundary layer increases. Figure 4 illustrates the velocity profile for different values of $\beta$ at $\eta_{\infty}=5$ when $m=0$ and $m=0.1$, respectively. Both the figures show the increasing behaviour of the 
fluid flow for the decreasing values of $\beta$ so that the boundary layer thickness increases. Figures 5-6 depict the energy profiles for $\varepsilon$ in the absence and presence of the pressure gradient $m$. From these figures, it is observed that the thermal boundary layer thickness decreases with the increasing values of $\varepsilon$. On comparing these three figures, one can note that the thermal boundary layer thickness decreases when the pressure gradient parameter $m$ increases from -0.2 to 0.2 and hence the thermal boundary layer thickness decreases.

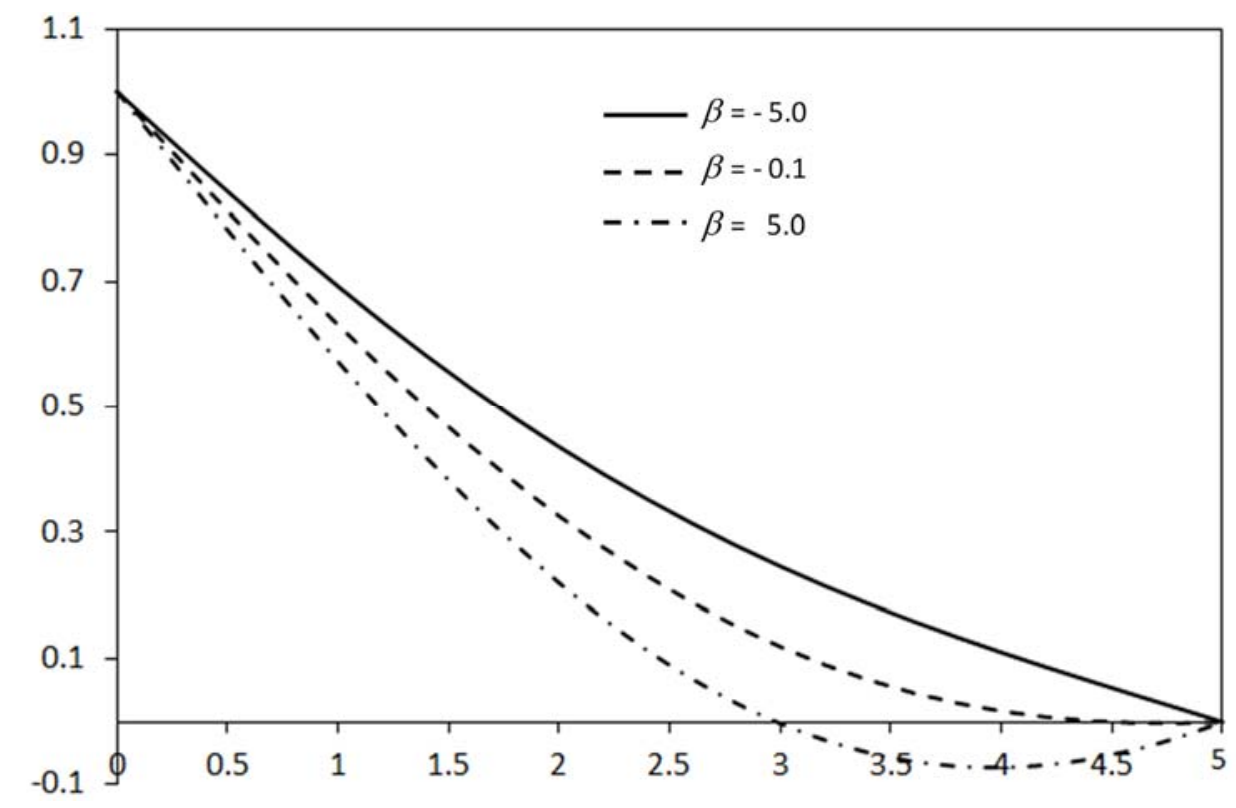

Fig.7. Energy profile for $\theta(\eta)$ for the different values of $\beta$ at $m=0.05, \varepsilon=0.1, \operatorname{Pr}=0.3$ and $\eta_{\infty}=5$.

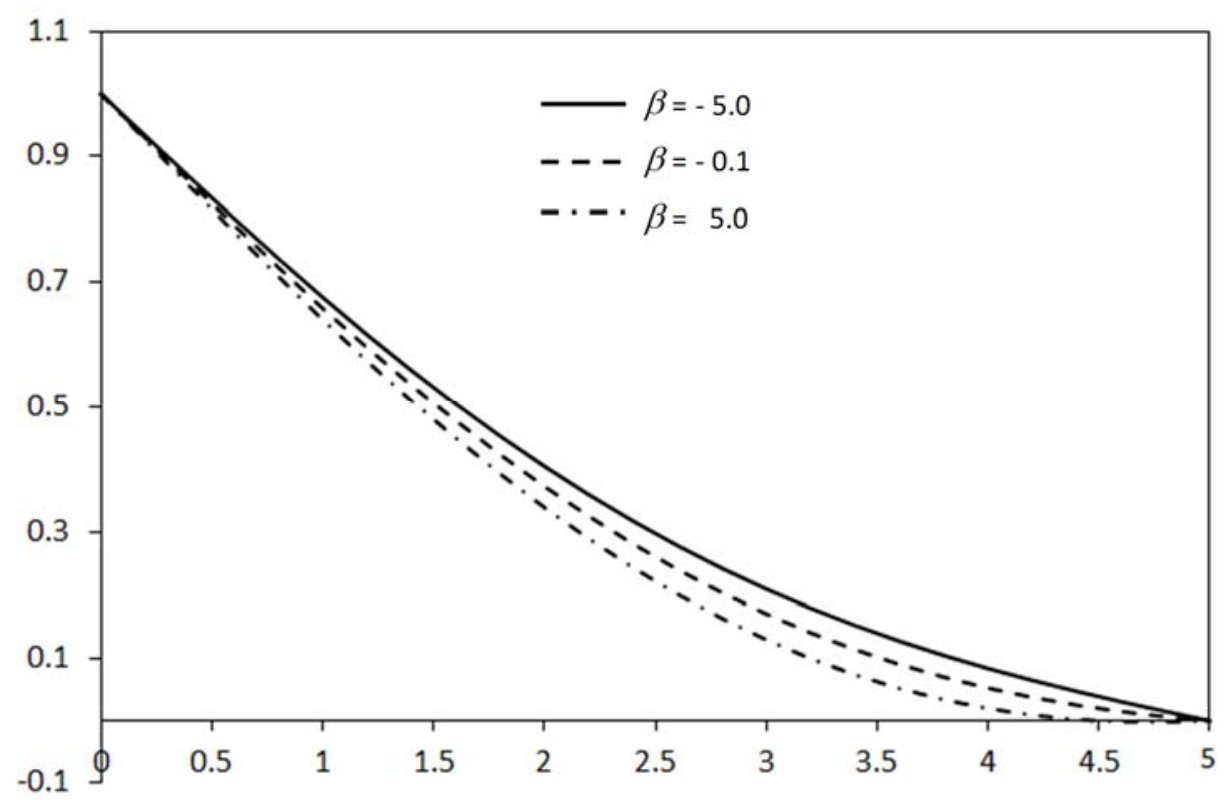

Fig.8. Energy profile for $\theta(\eta)$ for different values of $\beta$ at $m=-0.05, \varepsilon=0.1, \operatorname{Pr}=0.3$ and $\eta_{\infty}=5$.

Figures 7-8 show the energy profile for $\beta$ in the absence and presence of the pressure gradient $m$, respectively. Figure 7 shows that the thermal boundary layer thickness increases with the increasing values 
of $\beta$. On the other hand, in Fig.8., the behaviour of the thermal boundary layer thickness changed to a decreasing trend with the increasing values of $\beta$ which is the case in the presence of $m$ and hence the thermal boundary layer thickness decreases. In all two figures the values of $\beta$ range from $-5 \leq \beta \leq 5$. From Fig.7., it is noticed that the negative values of $\theta(\eta)$ for the value of $\beta=0.05$ lead to the fluid cooling case. Physically, this is possible when the fluid is cooled. The values $\beta>-0.1$ indicate the fluid becomes cooled. Figure 9 shows the energy profiles for different values of the Prandtl number Pr in the absence and presence of the pressure gradient $m$. In the specified circumstances, the thermal boundary layer thickness decreases. On the other hand, all of these three figures show the variation of energy profiles when the pressure gradient $m$ ranges from -0.2 to 0.2 and it is observed that the thermal boundary layer thickness decreases.

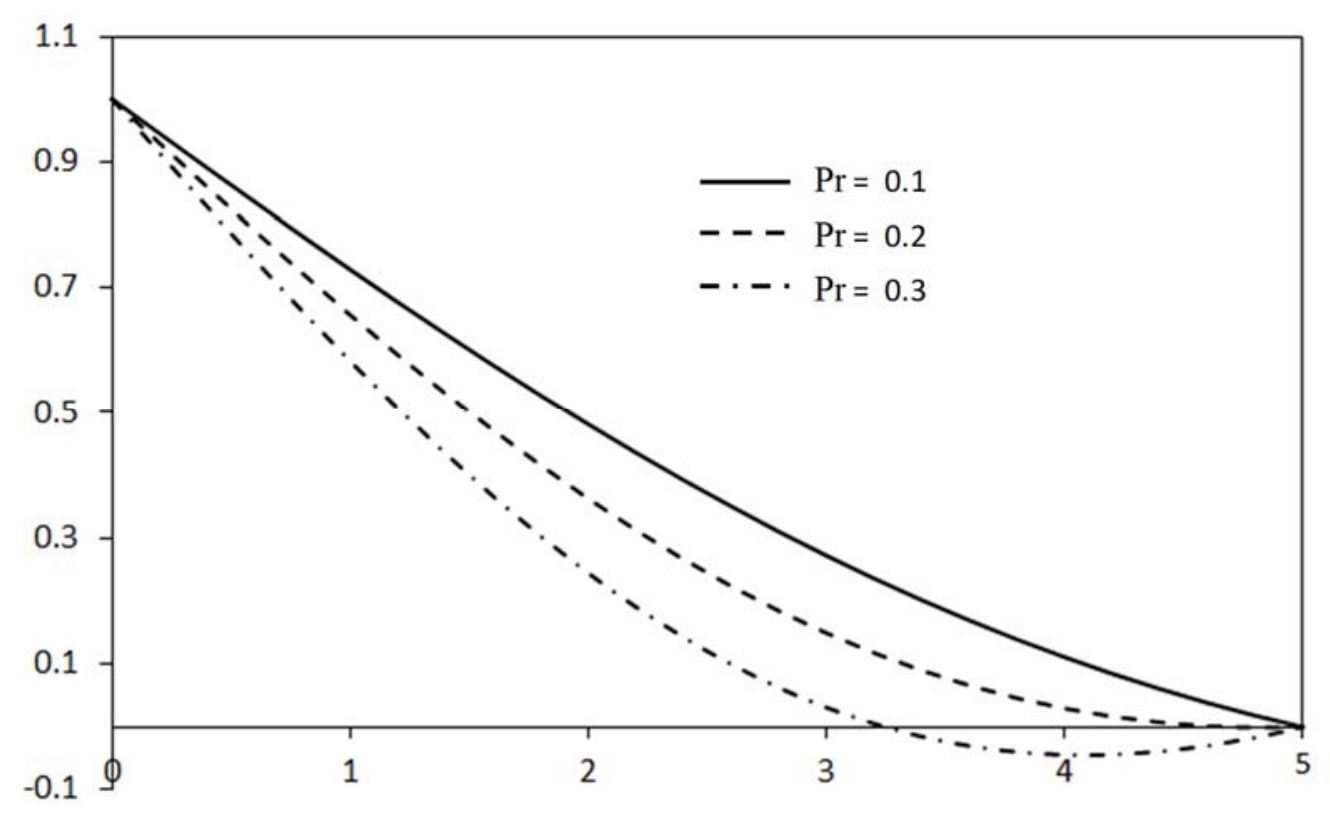

Fig.9. Energy profile for $\theta(\eta)$ for different values of $\operatorname{Pr}$ at $\eta_{\infty}=5, \varepsilon=0.1, m=0.2$ and $\beta=-0.1$.

It is clear from Fig.9. that the negative values of $\theta(\eta)$ for the value of $\operatorname{Pr}=0.3$ lead to the fluid cooling case. Physically, this is possible when the fluid is cooled. When the Prandtl number $\operatorname{Pr}>0.2$, the fluid cools down.

\section{Conclusion}

In this research problem, partial differential equations have been established for the convective heat transfer in the boundary layer flow of a Maxwell fluid over a stretching sheet in the presence and absence of the pressure gradient. To get a solution of such a problem, initially similarity transformation technique has been used to transform these equations into an ODE (Ordinary Differential Equation) and then an approximation technique has been implemented through an application of Adam and Gear Methods.

The results have been reported in the absence and presence of the pressure gradient for the sake of comparison. From the plots of velocity profiles $f^{\prime}(\eta)$, it is observed that the boundary layer thickness increases, except in the two cases where the boundary layer thickness decreases for the case of $\varepsilon$ in Figs 1 and 2. The thermal boundary layer thickness has decreased for all results, except in Fig.7. which shows that the thermal boundary layer thickness increased. As a whole, results indicate a significant thinning in the momentum and thermal boundary layer thickness in both velocity and temperature profiles. On the other 
hand, some figures exhibit negative values for $f^{\prime}(\eta)$ and $\theta(\eta)$ which indicate the case of fluid cooling. It is also noted that the momentum and boundary layer thickness decrease for non-zero values of the pressure gradient $m$.

\section{Acknowledgements}

The first author (ANK) thanks for the full financial support of the Federal Urdu University of Arts, Sciences \& Technology (FUUAST) Karachi, Pakistan under the Faculty Development Program (FDP) of Higher Education Commission (HEC) of Pakistan and thanks to Dr. Muhammad Arif Hussain who has given a great support in this research (affiliated to Mohammad Ali Jinnah University, Karachi, Pakistan).

\section{Nomenclature}

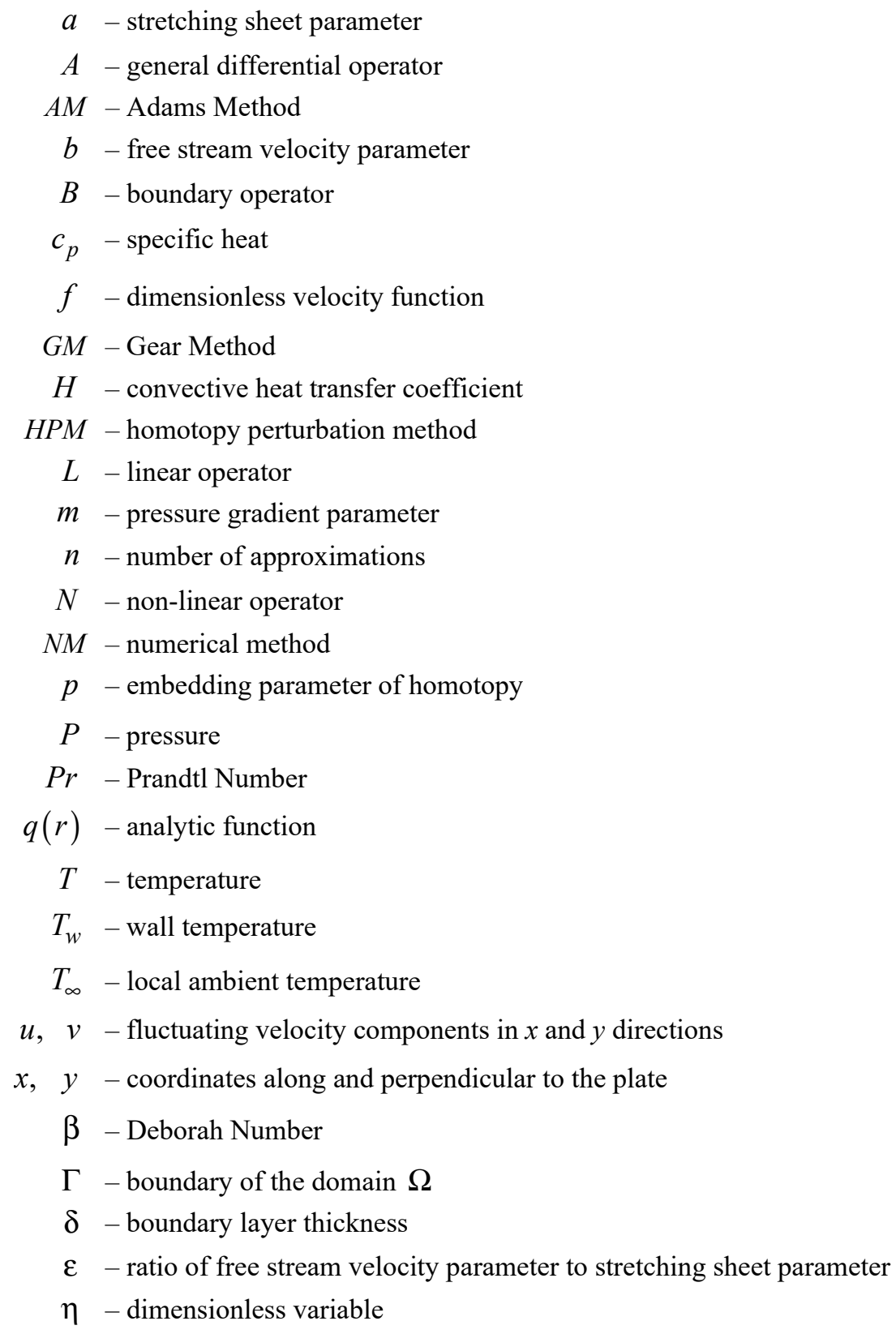




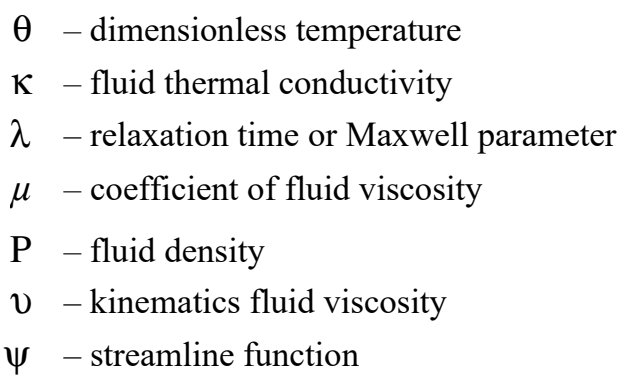

\section{References}

[1] Hayat T., Shehzad S.A. and Alsaedi A. (2012): Study on three-dimensional flow of Maxwell fluid over a stretching surface with convective boundary conditions.- International Journal of the Physical Sciences, vol.7, No.5, pp.761768.

[2] Bhattacharyya K., Hayat T. and Gorla R. (2013): Heat transfer in the boundary layer flow of Maxwell fluid over a permeable shrinking sheet.- Thermal Energy and Power, vol.2, No.3, pp.72-78.

[3] Fathizadeh M. and Rashidi F. (2009): Boundary layer convective heat transfer with pressure gradient using homotopy perturbation method (HPM) over a flat plate.-Chaos, Solitons \& Fractals, vol.42, No.4, pp.2413-2419.

[4] Aziz A. (2009): A similarity solution for laminar thermal boundary layer over a flat plate with a convective surface boundary condition.- Communications in Nonlinear Science and Numerical Simulation, vol.14, No.4, pp.1064-1068.

[5] Ishak A. (2010): Similarity solutions for flow and heat transfer over a permeable surface with convective boundary condition.- Applied Mathematics and Computation, vol.217, No.2, pp.837-842.

[6] Shagaiya Y. and Daniel S. (2015): Presence of pressure gradient on laminar boundary layer over a permeable surface with convective boundary condition.- American Journal of Heat and Mass Transfer, vol.2, No.1, pp.1-14.

[7] Surati H.C. and Timol M.G. (2010): Numerical study of forced convection wedge flow of some non-Newtonian fluids.- Int. J. of Appl. Math and Mech, vol.6, pp.50-65.

[8] Patel M. and Timol M.G. (2011): Numerical treatment of MHD Powell-Eyring fluid flow using the method of satisfaction of asymptotic boundary conditions.- International Journal of Mathematics and Scientific Computing, vol.1, No.2, pp.71-78.

[9] Hayat T., Iqbal Z., Qasim M. and Obaidat S. (2012): Steady flow of an Eyring-Powell fluid over a moving surface with convective boundary conditions.- International Journal of Heat and Mass Transfer, vol.55, No.7-8, pp.1817-1822.

[10] Malik R., Khan M., Munir A. and Khan W.A. (2014): Flow and heat transfer in Sisko fluid with convective boundary condition.- PLoS ONE, vol.9, No.10, pp.107-989.

[11] Singh V. and Agarwal S. (2014): MHD flow and heat transfer for Maxwell fluid over an exponentially stretching sheet with variable thermal conductivity in porous medium.- Thermal Science, vol.18, No.2, pp.599-615.

[12] Javed T., Ali N., Abbas Z. and Sajid M. (2013): Flow of Aneyring-Powell non-Newtonian fluid over a stretching sheet.- Chemical Engineering Communications, vol.200, No.3, pp.327-336.

[13] Shateyi S. (2013): A new numerical approach to MHD flow of a Maxwell fluid past a vertical stretching sheet in the presence of thermophoresis and chemical reaction.- Boundary Value Problems, vol.196, pp.1-14.

[14] Mukhopadhyay S. (2013): MHD boundary layer flow and heat transfer over an exponentially stretching sheet embedded in a thermally stratified medium.- Alexandria Engineering Journal, vol.52, No.3, pp.259-265.

[15] Bhattacharyya K. (2011): Dual solutions in boundary layer stagnation-point flow and mass transfer with chemical reaction past a stretching/shrinking sheet.- Int. Comm. in Heat and Mass Transfer, vol.38, No.7, pp.917-922.

[16] Ibrahim S.M. and Suneetha K. (2014): Radiation and heat generation effects on steady MHD flow near a stagnation point on a linear stretching sheet in porous medium in presence of variable thermal conductivity and mass transfer.- Int. J. Cur. Res. Acad. Rev, vol.2, No.7, pp.89-100.

[17] Rehman A. and Nadeem S. (2013): Heat transfer analysis of the boundary layer flow over a vertical exponentially stretching cylinder.- Global Journal of Science Frontier Research Mathematics and Decision Sciences, vol.13, No.11, pp.73-85.

[18] Saleh S., Arifin N., Nazar R., Ali F. and Pop I. (2014): Mixed convection stagnation flow towards a vertical shrinking sheet.- International Journal of Heat and Mass Transfer, vol.73, pp.839-848. 
[19] Ji-Huan H. (1999): Homotopy perturbation technique.- Computer Methods in Applied Mechanics and Engineering, vol.178, No.3, pp.257-262.

[20] Ji-Huan H. (2008): An elementary introduction to recently developed asymptotic methods and nano mechanics in textile engineering.- International Journal of Modern Physics B, vol.22, No.21, pp.3487-3578.

[21] Cveticanin L. (2006): Homotopy-perturbation method for pure nonlinear differential equation.- Chaos. Solitons \& Fractals, vol.30, No.5, pp.1221-1230.

[22] El-Shahed M. (2005): Application of He's homotopy perturbation method to Volterra's integro-differential equation.- International Journal of Nonlinear Sciences and Numerical Simulation, vol.6, No.2, pp.163-168.

[23] Esmaeilpour M. and Ganji D. (2007): Application of He's homotopy perturbation method to boundary layer flow and convection heat transfer over a flat plate.- Physics Letters A, vol.372, No.1, pp.33-38.

[24] Ghori Q., Ahmed M. and Siddiqui A. (2007): Application of homotopy perturbation method to squeezing flow of a Newtonian fluid.- International Journal of Nonlinear Sciences and Numerical Simulation, vol.8, No.2, pp.179-184.

[25] Mahmood M., Hossain M., Asghar S. and Hayat T. (2008): Application of homotopy perturbation method to deformable channel with wall suction and injection in a porous medium.- International Journal of Nonlinear Sciences and Numerical Simulation, vol.9, No.2, pp.195-206.

[26] Siddiqui A., Ahmed M. and Ghori Q. (2006): Couette and Poiseuille flows for non-Newtonian fluids.- Int. J. of Nonlinear Sci. and Numerical Simul, vol.7, No.1, pp.15-26.

[27] Fan J., Shi J. and Xu X. (1999): Similarity solution of free convective boundary-layer behaviour at a stretching surface.- Heat and Mass Transfer, vol.35, pp.191-196.

[28] Ishak A. (2010): Unsteady MHD flow and heat transfer over a stretching plate.- Journal of Applied Sciences, vol.18, pp.2127-2131.

[29] Bhattacharyya K., Mukhopadhyay S. and Layek G. (2012): Effects of partial slip on boundary layer stagnation point flow and heat transfer towards a stretching sheet with temperature dependent fluid viscosity.- Acta Technica, vol.57, pp.183-195.

[30] Bhattacharyya K., Mukhopadhyay S. and Layek G.C. (2011): Slip effects on an unsteady boundary layer stagnation-point flow and heat transfer towards a stretching sheet.- Chin. Phys. Let, vol.28, No.9, pp.1-5.

[31] Motsa S.S. and Sibanda P. (2012): On the solution of MHD flow over a nonlinear stretching sheet by an efficient semi-analytical technique.- Int. J. Num. Meth. Fluids, vol.68, pp.1524-1537.

[32] Rahman M.M., Rahman M.A., Samad M.A. and Alam M.S. (2009): Heat transfer in a micropolar fluid along a non-linear stretching sheet with a temperature-dependent viscosity and variable surface temperature.International Journal of Thermophysics, vol.30, No.5, pp.1649-1670.

[33] Hayat T., Shehzad S.A., Alsaedi A. and Alhothuali M.S. (2012): Mixed convection stagnation point flow of Casson fluid with convective boundary conditions.- Chinese Physics Letters, vol.29, No.11, pp.114-704.

[34] Kazem S., Shaban M. and Abbasbandy S. (2011): Improved analytical solutions to a stagnation-point flow past a porous stretching sheet with heat generation.- Journal of the Franklin Institute, vol.348, No.8, pp.2044-2058.

[35] Weisstein E.W. (2021): Adams method.- URL From Math World, A Wolfram Web Resource, http://mathworld.wolfram.com/AdamsMethod.html

[36] Wolfgang C. (2007): Gear method.- The Journal of Gear Manufacturing, University of California, San Diego, http://renaissance.ucsd.edu/chapters/chap11.pdf

[37] Matthew B., Olyvia D., Viral P., Joel S., Van Eric B. (2007): Adams and gear methods for solving odes with mathematica.- URL https://controls.engin.umich.edu/wiki/ index.php/Solving ODEs with Mathematica

[38] Kaka C.S. and Yener Y. (1980): Convective Heat Transfer.- Middle East Technical University, p.432.

[39] Eosboee M., Pourmahmoud N., Mirzaie I., Khameneh P.M., Majidyfar S. and Ganji D. (2010): Analytical and numerical analysis of MHD boundary layer flow of an incompressible upper-convected Maxwell fluid.International Journal of Engineering Science and Technology, vol.2, No.12, pp.6909-6917.

[40] Abbas Z., Wang Y., Hayat T. and Oberlack M. (2010): Mixed convection in the stagnation-point flow of a Maxwell fluid towards a vertical stretching surface.- Nonlinear Analysis: Real World Applications, vol.11, No.4, pp.3218-3228.

Received: May 26, 2021

Revised: July 16, 2021 